\title{
The Drawbacks of Rural Development in a Developing Country
}

\section{Introduction}

Development, and more especially "Rural" development is an emotive subject which conjures up, in the developed countries, professionally prepared publicity posters of the emaciated child, or the woman drawing drinking water from a stream polluted by humans and livestock alike. They are stimulus of "give" to the less privileged.

And what of the "less privileged"? To them, it is also an emotive subject, sans the publicity posters. They are not needed to reinforce the deficiencies of a life style which is a continual struggle, draining the spirit and crushing the will to fight for their own survival. Apathy is the travelling companion of deprivation.

Rural development is much talked about. Many people think that they have the solutions - some proposed from a political doctrinaire standpoint, others from humanitarian considerations. I personally believe that all political doctrines are themselves developed as a means to combat and minimise the effect of human egoism and dishonesty and if everyone was sincere and honest and caring for their fellow beings, there would be little difference between, or even little need for the various political doctrines. Essentially, Rural Development is material and technical assistance given to rural village communities to improve their quality of life, both socially and economically. It can be to produce more food to alleviate hunger, to provide clean water to eliminate disease, or to provide means of supplementing a meagre cash income - usually a combination of all of these factors, plus many more, all related directly or indirectly to farming as a way of life.

Before discussing the Drawbacks of Rural Development in a Developing Country I feel that it is necessary to summarise what should be the guiding principles while preparing projects:

1. Assistance from the public and participation from the villagers should be sought.

2. The development agency should act as a catalyst between the public and the village organisations. If there is no village organisation (as is the case in most of the villages) then these objectives will be achieved through the village headmen, village leaders, school teachers, religious leaders or directly through private individuals.
3. Special importance should be placed on the optimum usage of finances, the technical aspects of the task at hand and the local labour force for completing projects.

4. The social and economic unity of the villages should be preserved.

5. Activities should be planned so that they can be integrated with each other as much as possible.

6. The programme should include short, mid- and long-term solutions to problems.

7. In some cases only poor families in the villages should be selected, while in other cases, to achieve unity in the service, all of the villagers should be assisted.

I quote here a programme of activities followed by a development agency in Eastern Anatolia (Van and Environs Development Foundation - VEDF):

1. Improvement of Animal Husbandry

1.1 Encouragement to Use Concentrated Factory Feed

1.2 Animal Husbandry and Disease Control

1.3 Improvement of Forage Crops

1.4 Improvement of Milk Goats

1.5 Production and Marketing of Dairy Products

2. Adaptation of New Winter Wheat Types to the Region

3. Disease and Insect Control in Alfalfa and Other Plants

4. Establishment of Fruit Orchards and Vineyards

5. Education and Health Services

5.1 Scholarships

5.2 School Construction

5.3 Aids for Schools and Training

5.4 Portable Libraries

5.5 Supplying Drinking Water to the Villages

5.6 Health Services

5.7 Building Toilets in the Villages

6. Support of Local Organisations and Village Social and Economic Activities

Ahmet Akyürek, M. S. PhD, Associate Professor, Faculty of Agriculture, Yüzüncü Yıl University and President, Van and Environs Development Foundation, P.K. 77, Van, Turkey 
6.1 Support for Cooperatives

6.2 Other Activities

6.3 Special and Unexpected Activities for the Afghan Refugees

\section{The Role of Development Agencies}

Put very simply, this is to provide the stimulus, the organisational infrastructure and initially, the means to carry out development work. While, ideally, the development work should be carried out by the people themselves, the target beneficiaries, it is generally recognised that because of apathy and lack of incentive and organisation, this is rarely feasible. The development agency acts as the catalyst in the reaction and it should be possible to withdraw it at the end of the project period leaving the "assisted» community to carry on the work alone.

Development agencies may be either private foundations or governmental departments. Government, in practise, is the main development agency in most countries because not only does it possess the resources to carry out development work on a scale far in excess of any private organisation, but because of its essential nature, government must be involved in the approval of any project in the area under its jurisdiction - especially in an age when increasing population demands greater national control and planning.

Projects undertaken by private foundations (the private sector) are generally more successful in achieving their objectives because they are less extensive in their scope and more flexible in operation. But it is imperative that the private sector works closely with government departments in the same field, for example, in agriculture.

The role of the private sector vis-à-vis government agencies is to:

1. Initiate and undertake sub-projects for the government.

2. Create a new model for project implementation.

3. Undertake joint projects with the government utilising the flexibility of the private sector and the resources of the government.

What form should development work take? This question revolves around the social and economic aspects of development. Most people want, ultimately, economic development - projects which set out to cater for the social aspirations of a community health hygiene and education - find they ultimately have to cater for economic needs. Conversely, projects which embark upon economic development find that social factors cannot be neglected and they may even limit or render ineffective major economic development.

Rural development projects, in spite of their interrelated social and economic factors demand clearly defined objectives on the part of the organisation involved if their efforts are not to be dissipated on too broad a front, resulting in a less than satisfactory impact. Success stimulates success and if simple objectives can be achieved, it builds up the confidence of project staff and target beneficiaries encouraging them to strive for further success.

On a personal note, I myself prepared a rural development programme for the earthquake area in Eastern Anatolia after 1976, and found to my surprise that I could actually implement only $30-40 \%$ of my own plans. Why?

Principally, the low application percentage was due to my lack of practical field experience, which resulted in projects being prepared in a manner which was difficult to implement later. I had a university background, which was largely theoretical, and while I could identify on paper the solution to a problem, the human factor and its environmental drawbacks could not be predicted. I had worked at Erzurum Atatürk University (also in Eastern Anatolia) and I thought I knew the people of Eastern Turkey and could easily persuade them to help themselves. This, however, proved to be much more difficult than expected because they had developed a "Disaster Psychology" which I didn't anticipate... where they were prepared to simply look on passively while development workers carried out the work for them. I also discovered that the success of the projects were not only dependent upon me or my organisation but also upon other organisations, especially those run by the government. That was my personal introduction to the Drawbacks of Rural Development in a Developing Country.

\section{What are the Drawbacks?}

While one needs to be positive in thinking about rural development, it is, at the same time, necessary to have a clear understanding of the constraints under which work is carried out, i. e. one must consider the drawbacks. This is especially important for the donor agencies, which at the end of the day, must know if thı :ir money is being effectively utilised in assisting the $t_{t}$ rget beneficiaries. I consider the following points of najor importance:

\section{Proje :t Preparation with Inadequate Information}

Grod p oject planning is a prerequisite for success... while a well-planned project may fail at the implementation stage, a badly planned project is doomed to failure before it even begins. Yet many rural development projects are prepared and planned with little detailed knowledge of the community to be assisted. Why? The planners are usually experts from outside the community, perhaps foreigners, who, while they are experienced in general development work, may 
still lack detailed knowledge of the customs, culture and problems of the community to be aided, and have to prepare the project on the basis of information collected during one or two brief visits on which they are escorted around by local officials and are not free to study the problems in depth. These visits are usually made at the time when travel is easy - which again coincides with the time when the extent of the real problems is not evident; leaving the expert dependent upon information given by both local government officials and the community. The former usually control the information given so that it does not reflect discredit upon themselves, while on the other hand, villagers think that by exaggerating the true facts of any situation they will receive more aid and attention.

\section{2. "Central" Planning}

While "Central" planning is a necessary function of large organisations such as governments, it has serious limitations when implementing projects at the local level. By its very nature it can take little or no consideration of the differing social and geographic needs of small communities, which can best be catered for by a series of small sub-projects implemented by independent development agencies or boards. A major drawback in any developing country is the inflexible bureaucracy which acts irrespective of the local needs. It is recognised that, in a large centrally planned project, one cannot waste valuable time in seeking individual opinions, at the same time there must be adequate publicity of the aims of the project and an opportunity for representatives to make the community views known.

In fact, the community, when confronted with the mass of officialdom, may lack the courage to make their real views known to the central government and meekly acquiesce to whatever fate awaits them! There is a "happy medium" in rural development work between the arbitrary imposition of an overall plan, and attention to every local, probably prejudiced, need and demand. It is essential to show tact, sympathy and understanding of their point of view, even if it is not possible to cater for it.

\section{3. "Crossed Lines - No Communication!"}

Where more than one development agency, or more than one department, is involved in any project, there are inevitably communication problems. Perhaps hostility, where each is trying to be more successful than the other, for personal or financial reasons. There is lack of data-sharing and lack of coordinated planning, where there should be close cooperation. Why? Frequently the fault lies at the top, where personality problems emerge and where leaders seek to expand their own influence like rival commercial companies marketing similar products. To reach the top, a certain aggressiveness of character and personal ambition is needed which must be tempered and controlled in a good leader, and it certainly must not be displayed at the field level. Donor agencies can help maximise efficiency in development work by regular field visits and by an interest in what other agencies are doing - a regular interchange of plans and ideas is needed in the interests of the target beneficiaries if there is a genuine concern for their welfare. Frequently two development agencies find that they are "assigned" the same area (by government) thus duplicating effort - or, if it is a difficult assignment, each one leaves it to the other to carry out.

\section{4. "Big is Beautiful" Syndrome}

It is easier to obtain finances for a large scale project than a small scale one, which, at the field level are usually more cost effective and can operate with low overhead expenses! Donor agencies find it more worthwhile, generally, to finance larger projects because on their part the same number of supervision visits may be desirable. Two sides of the coin. The "Big is Beautiful" concept is unfortunate, because it discriminates against the small development agency who wishes to implement realistic, low cost development plans, such as basic health and education programmes rather than be overambitious and build roads and supply routes. In any case, the opening up of transport routes normally follows as a logical sequence to primary development.

\section{Motivation for Aid}

At the government level much aid is given equally for political and humanitarian reasons - so in some countries of strategic importance, the actual giving of the aid is more important than the way it is used. This gives rise to a situation where a government development agency may be less answerable to the donor agency than would a local private or voluntary organisation. Because of this, there is obviously a greater incentive for the private or voluntary agency to be successful and efficient in its use of resources - which in turn leads to greater flexibility and care in the project preparation and implementation, and use of funds.

\section{Field Staff}

It is the men and women working at field level who ultimately hold the success or failure of the development project. Theirs is the task of gaining the confidence of the people they are trying to help, people who are traditionally suspicious of new projects and new ideas, and whose attitude tends to be "What's in it 
for them?" It requires patience and dedication, and above all honesty and integrity of character to succeed in such a situation - and there is little status or financial reward in this work.

These are local national personnel, working in their own country where they are inevitably under great pressure to "succeed" in life, so that they can repay the "debt" incurred by their family in having them educated, often at great sacrifice by other members. A person must be highly motivated and strong of character to leave a potentially "successful" career to work in rural villages!

Unfortunately, in government development agencies where people are "posted" to an area, unless there is a strong financial inducement for them to stay, most wish to transfer to a more amenable, i. e. city-post, and consequently spend the time when they should be in the field, instead at the regional or head office lobbying for a "transfer". And in the process, leaving their own office bereft of transport and of the key person to sign papers or open the supply store, thus hindering development! This is an all too familiar pattern. Or they can become autocratic and overbearing, adding only more problems to the lives of the people that they are theoretically helping.

\section{Community Attitudes}

Typically, the "target beneficiaries" are traditional, conservative and resistant to change - unless the benefits thereof can be demonstrated physically, and experienced. They won't change on the strength of promises alone - a mistrust in part due to the extravagant and often totally unrealistic and unattainable promises made by politicians and government officials to suit their own (temporary) ends. Traditional mistrust of those who come to "help" frequently stems from ignorance - it is something they may never have hitherto experienced in their harsh surroundings where, in order to survive, the richer exploit the poor and the poor exploit the very poor. Life is tough, and only the fittest can survive - and a "welfare state" is beyond their comprehension.

Equally difficult for the development agency is the failure of village communities to honour promises on the assumption that once a project begins, it must finish. They will promise help and assistance, only to get the work begun, without ever intending to keep their promises. Local participation in any development situation is vital in order that the community may recognise it as "their" project, and thus take more interest in its success. It will increase their self respect, boost their morale and give them a pride in achievement.

Also difficult is the "Disaster Mentality" - a state of shock and despair often associated with natural disasters such as floods, famine and earth-quakes. The affected community, which has usually suffered great loss, will fatalistically wait for everything to be done for them. Or not done. If permitted, they will resignedly endure deprivation, leaving up to the development agency to carry out reconstruction. These communities must be forced to help themselves because the Disaster Mentality is self-destructive if allowed to flourish.

\section{8. "Link" Man}

A key man (perhaps assisted by a committee) who acts as liaison between the community and the development agency. This man is needed, in addition to dedicated field staff. Generally, in practise, the people with most influence tend to be the older and more conservative members of the community, perhaps religious or tribal leaders, who are opposed to change - and it is the younger educated people such as the local school teacher (who may not find favour with the traditional hierarchy) who is the most valuable "link man" in development work. Firmness and tact, sympathy and understanding are needed by people in development agencies to avoid the potential and ever present danger of conflict between tradition and progress.

\section{Factions in Community Life}

Factions, polarised loyalties and interfamily rivalry are found in all strata of society. In development work at the community level they can be a major hindrance because if one party supports a project, the other almost automatically opposes it. While this does present the development agency with the role of peacemaker to secure cooperation on a much needed facility, in practise this rarely happens because rivalry is too deep-seated (which is why, in practise, village cooperatives are rarely successful in the long-term). Rich factions and families also exist in communal life and they usually hold such influence over the poor that it is necessary for the development agency to also assist them - or, to put it bluntly, "buy" their support! It is like having to melt the ice on a frozen stream to get to the water; permissable, I feel, in order to preserve the "integrity" of the community.

\section{The Appraisal of Development Projects}

The appraisal of a development situation must consider the short, medium and long-term needs of a community. It is rarely sufficient to simply implement one aspect of a situation, because this leads to an imbalance. Similarly, while short-term solutions are attractive and usually necessary, it is only the longterm solution which will ultimately benefit the community. The eradication of the cause of the 
problem is necessary! There must be a total and integrated effort to ensure the optimum impact and optimum effect for any one component. For example, it is counter-productive to try to increase livestock numbers without increasing forage production and improving disease control. All factors must be considered in the light of the long-term developments.

\section{The Criteria and Attainment of Success}

This is, for the donor and the development agency, the final reckoning - the "bottom line". Has the "aim" of the project been realised? How successful has it been? Further financial aid and the jobs of permanent donor and development agency personnel may depend on this answer. It is obviously an emotive issue - and everyone, the public and private sectors alike, want success. Which in turn puts pressure on the staff of development agencies, who are often the judges of their own efforts.

The result is that in order to attract financial support, development (and donor) agencies frequently "gloss over" the failures and emphasise what they regard as success - an assessment which is not always objective!! Few organisations are willing to put their reputation "on the line" by setting out clear and realistic objectives. Some organisations set out deliberately low objectives in order to claim exceptional success by exceeding their target. Others set out deliberately vague objectives so as not to be "pinned down" if they don't succeed. And much of this attitude stems from the public's demand for "success at all costs" - success and no failure!! In the ultimate case this leads to the public being fed distorted information because they find the truth unpalatable.

The donor agencies have a role in correcting this by educating the public to an honest acceptance and an impartial appraisal of results. Objectives must be clearly established and then the attainment assessed objectively, preferably by experienced technical development personnel. This can be painful and salutary but it is owed to both the people who give the help, and those for whom it is given.

Part of the objective of this paper is to educate the public into the behind-the-scenes realities of a development situation, so that they can appreciate the results of honest endeavour, in an informed and enlightened manner, in a field situation which is far from ideal but needs help. The "success at all costs" craving is both damaging and shortsighted as a policy for any organisation, and could ultimately tarnish the reputation of both donor and development agency alike.

I have outlined the drawbacks, not, I hope, in a negative sense, but with a plea for more informed, involved and enlightened interest on the part of those who give so generously of time and material goods to help meet the needs of rural communities in need of development.

\section{Acknowledgements}

I want to thank Mr. A. Leemann, Head of the Geography Department at Zürich University and Mr. Paul J. Loosli from Swiss CARITAS for encouraging me to prepare this paper and arranging for me to give a speech on this topic at the Geography Department of Zürich University.

\section{Zusammenfassung}

Der Autor geht den Gründen nach, die eine landwirtschaftliche Entwicklung in Drittweltländern oft verzögern oder gar verhindern. Er betont, wie wichtig es sei, schon vor der Ausarbeitung eines Projektes mit der Dorfbevölkerung Kontakt aufzunehmen (wobei der Wahl des richtigen Verbindungsmannes grosse Bedeutung zukommt), um die wirklichen Bedürfnisse abzuklären. Gerade bei staatlicher Entwicklungshilfe werden aus Prestigegründen einseitige Informationen eingeholt oder einfach Grossprojekte gegenüber kleinräumiger Hilfe bevorzugt, die jedoch der jeweiligen Situation besser angepasst und erfolgreicher wäre (das «big is beautiful»-Syndrom).

An die Personen, welche direkte Feldarbeit leisten, müssen hohe Ansprüche hinsichtlich Einfühlungsvermögen, Takt, Geduld und Beharrungsvermögen gestellt werden, um der Gefahr eines Konfliktes zwischen Tradition und Fortschritt vorzubeugen, der zu Rivalitäten führen kann und damit das Projekt gefährdet. Oft werden auch nur die meist attraktiveren Kurzzeit-Bedürfnisse abgedeckt, ohne sie in den Rahmen von mittel- und langfristigen Lösungen $\mathrm{zu}$ stellen, was zu ständig zunehmendem Ungleichgewicht führt.

(Redaktion) 